\title{
O potencial da verificação automatizada baseada em regras para as medidas de segurança contra incêndio em BIM
}

\author{
The potential of automated rule-based verification for \\ fire safety measures in BIM
}

\section{Marcel Kater \\ Regina Coeli Ruschel}

\section{Resumo \\ $\mathbf{E}$} ste estudo objetiva a operacionalização do método de Eastman et al. (2009) aplicado à modelagem e à verificação automatizada das regulamentações de incêndio do estado de São Paulo com a Modelagem da Informação da Construção (BIM). O método adotado foi o da pesquisa construtiva. O processo de avaliação da solução aplicou a proposta na verificação de projeto de prédio residencial em formato " $H$ " de cinco andares para habitação de interesse social amplamente construído pela Companhia de Desenvolvimento Habitacional e Urbano no estado de São Paulo. Os artefatos resultantes são: (i) o conjunto de regras de verificação automatizada das medidas de segurança contra incêndio para edificação com área superior a $750 \mathrm{~m}^{2}$ e altura entre $6 \mathrm{~m}$ e $12 \mathrm{~m}$, que pode ser replicado para 90,8\% das alturas restantes; (ii) a hierarquia entre regras que disciplinam a coordenação da aplicação dos vários módulos e regras sobre o objeto de estudo; (iii) a descrição da preparação necessária do modelo BIM; e (vi) o esclarecimento do subconjunto de objetos do modelo e propriedades necessárias para o processo de verificação automatizada, que fornece indicativos de um Model View Definition (MVD) específico para essa verificação de código. A solução desenvolvida possibilitará maximizar a aplicação de legislações e regulamentações relacionadas às medidas de segurança contra incêndio em edificações.

Palavras-chave: Segurança contra incêndio. Verificação de códigos. Automação de regras. Códigos. BIM. Solibri Model Checker.

\begin{abstract}
The aim of this study is the operationalisation of Eastman et al.'s (2009) code checking method applied to the modelling and automated verification of fire regulations for multifamily residential units in the state of São Paulo, using specific BIM tools. The method adopted was constructive research. The solution evaluation process applied the methodology in the verification of a five-stories $H$ shaped residential building in a social housing project built by the Housing and Urban Development Company of the state of São Paulo. The resulting devices are as follows: (i) a set of rules for fire safety code-checking for buildings with an area of over $750 \mathrm{~m}^{2}$ and a height of $6 \mathrm{~m}$ to $12 \mathrm{~m}$, which can be replicated to $90.8 \%$ of the remaining heights; (ii) a hierarchy to guide the coordination of the application of the various modules and rules on the object of study; (iii) a description of the required preparation of the BIM model; and (vi) clarification of the subset of model objects and properties needed for the automated verification process, which provides indications of a specific Model View Definition (MVD) for this code checking. The solution developed will make it possible to maximise the application of laws and regulations related to fire safety measures in buildings.
\end{abstract}

${ }^{1}$ Marcel Kater ${ }^{1}$ Universidade Estadual de Campinas Campinas - SP - Brasil

${ }^{2}$ Regina Coeli Ruschel 2Universidade Estadual de Campinas Campinas - SP - Brasil

Recebido em 02/04/19 Aceito em 12/01/20
Keywords: Fire safety. Code checking. Rules automation. Standards. BIM. Solibri Model Checker. 


\section{Introdução}

Segundo Yalcinkaya e Singh (2015), a temática de verificação automatizada de códigos (automated code checking) é a principal no contexto da Modelagem de Informação da Construção (Building Information Modeling - BIM) aplicada à verificação de requisitos de projeto e sua conformidade com códigos. Os temas de pesquisa sobre transformação de modelos e identificação de riscos de segurança também se equiparam.

Para Eastman et al. (2009), o potencial da verificação automatizada baseada em regras com BIM é enorme, sendo aplicável por agências que visam ao cumprimento de códigos ou por organizações e clientes com um tipo específico de edificação. Santos, Costa e Grilo (2017) observaram que estudos que cobrem a verificação automatizada de códigos, por regras e análise de padrões, têm ganhado força nestes últimos anos. Essa tem sido a abordagem de maior ênfase nas pesquisas brasileiras nessa temática (BALDAUF, 2013; TAKAGAKI, 2016; MAINARDI NETO, 2016; ANDRADE E SILVA, 2017; SILVA JUNIOR; MITIDIERE FILHO, 2018; FERNANDES; FORMOSO; TZORTZOPOULOS-FAZENDA, 2018; SOLIMAN JUNIOR, 2018).

Solihin e Eastman (2015) categorizam as regras de verificação em quatro classes:

(a) regras baseadas em dados explícitos;

(b) regras baseadas em valores derivados;

(c) regras que necessitam de dados estruturados; $\mathrm{e}$

(d) regras que requerem a prova de uma solução específica.

Compreende-se a quarta classe de regra como subjetiva. Mainardi Neto (2016) estende a compreensão e a classificação sobre regras subjetivas. Essas categorizações permitem diagnosticar o quão representável por regras é um conjunto de requisitos de projeto ou regulamentos normativos.

Baldauf (2013) propõe um método que integra a modelagem em BIM da solução projetual e a validação correspondente dos requisitos de clientes de empreendimento de habitação de interesse social. Utilizou-se o aplicativo dRofus de gestão de requisitos e de validação de soluções desenvolvidas em BIM. O método visa apoiar os processos de tomada de decisão durante as fases de desenvolvimento de projeto ou a avaliação de projetos finalizados. Entre as contribuições do estudo está a identificação dos requisitos de projeto que podem ser verificados automaticamente, assim como as mudanças e benefícios para o gerenciamento de requisitos quando se integra a modelagem à verificação automatizada. Esse estudo é sintetizado em Baldauf, Formoso e Miron (2013).

Takagaki (2016) implementou na plataforma Solibri Model Checker um conjunto de regras de verificação e validação de recomendações normativas de sistemas prediais de esgoto sanitário, água fria e água quente. As recomendações foram interpretadas e resumidas em vinte e sete verificações, parcialmente traduzidas em regras do aplicativo. Identificou-se a necessidade de ferramental extra para a implementação completa em $48 \%$ das recomendações escolhidas para automação.

Fernandes, Formoso e Tzortzopoulos-Fazenda (2018) desenvolveram um conjunto de verificação de regras, também no Solibri Model Checker, representativo dos requisitos normativos de especificações mínimas do Ministério das Cidades para unidades habitacionais do Programa Minha Casa, Minha Vida (PMCMV). O método de verificação automatizada proposto foi aplicado em dois projetos de empreendimentos do PMCMV. Vinte e oito por cento das regras do conjunto pretendido para a verificação não puderam ser implementados por limitações do aplicativo e da modelagem BIM ou subjetividade dos requisitos.

Andrade e Silva (2017) tentou automatizar a verificação de conformidade com a norma brasileira de desempenho para edificações habitacionais em empreendimentos do PMCMV por meio da plataforma Solibri Model Checker. O estudo constatou redução de tempo de conferência dos projetos e ainda apontou maior número de não conformidades comparativamente ao método de conferência manual. Diferentemente, Silva Júnior e Mitidieri Filho (2018) propõem uma forma de incorporar na própria ferramenta de modelagem BIM a verificação de critérios de desempenho em projetos de arquitetura de edificações habitacionais. Ambas as formas de implementação, por aplicativo de verificação de modelos ou por recursos nativos da ferramenta de modelagem BIM, codificaram aproximadamente um terço dos requisitos de projeto da norma pela checagem de forma automatizada.

Soliman Junior (2018) apresentou um sistema conceitual com base na abordagem semântica para fornecer suporte ao desenvolvimento de sistema de verificação automatizada. A contribuição desse trabalho está na taxonomia desenvolvida e na identificação das transformações necessárias para a conversão de regulamentações em regras lógicas parametrizáveis. 
A presente pesquisa é similar aos desenvolvimentos de Takagaki (2016), Andrade e Silva (2017) e Fernandes, Formoso e Tzortzopoulos-Fazenda (2018), e pioneira no contexto da verificação automatizada de regras abrangido, isto é, o código de segurança contra incêndio. Outro destaque é que, em vez de propor um método de verificação por regras, ela aplica um método referencial estabelecido por Eastman et al. (2009). Assim, este estudo objetiva a operacionalização, ou instanciação, do método de Eastman et al. (2009) para regulamentações de incêndio no estado de São Paulo para edificações de uso residencial privativo multifamiliar, fazendo uso de ferramentas BIM específicas. Dessa forma, a questão de pesquisa é avaliar o quanto essa abordagem é capaz de propor um processo automatizado de verificação de código das legislações estaduais (IT), municipais (COE) e normas de incêndio no contexto brasileiro (NBR), cuja verificação de projetos ainda se encontra majoritariamente manual.

\section{Referencial teórico}

\section{Leis e regulamentações de segurança contra incêndio em edifícios de uso residencial privativo multifamiliar}

De acordo com Seito (2009), no Brasil as legislações e as regulamentações para a verificação dos requisitos de segurança contra incêndio em edificações são analisadas nos âmbitos federal, estadual e municipal. A legislação federal, por meio da Portaria MTB nº 3.214 (BRASIL, 1978), consolidou-se as leis trabalhistas relativas à segurança do trabalho, cabendo ao extinto Ministério do Trabalho e Emprego, hoje incorporado ao Ministério da Economia, criar Normas Regulamentadoras (NR) que estabeleçam que o local de trabalho seja seguro ao trabalhador. Deve-se também seguir regulamentos estaduais e códigos municipais. Por exemplo, no estado de São Paulo, pelo Decreto estadual no 63.911 (SÃO PAULO, 2018), as análises, vistorias e aprovações cabem ao Corpo de Bombeiros da Polícia Militar do Estado de São Paulo (CBPMESP). Como exemplo municipal há o Código de Projetos e Execuções de Obras e Edificações do Município de Campinas (CAMPINAS, 2003). Essas legislações também variam para o tipo de edificação.

A legislação estadual de segurança contra incêndio, como relata Seito (2009), é elaborada pelo Corpo de Bombeiros de cada estado. No estado de São Paulo, o Decreto estadual nº 63.911 (SÃO PAULO, 2018) dispõe sobre as medidas de segurança contra incêndio nas edificações e áreas de risco, e tem por objetivo proteger a vida dos ocupantes dessas edificações e áreas de risco, dificultar a propagação do incêndio, reduzindo danos ao meio ambiente e ao patrimônio, proporcionar meios de controle e extinção do incêndio, dar condições de acesso para as operações do corpo de bombeiros e proporcionar a continuidade dos serviços nas edificações. Para efeito desse decreto, a Instrução Técnica do Corpo de Bombeiros (ITCB) é o documento técnico elaborado pelo CBPMESP que regulamenta as medidas de segurança contra incêndio nas edificações e áreas de risco (CORPO..., 2011).

O decreto estadual estabelece o que deve ser implantado nas edificações, os objetivos, os conceitos gerais de segurança contra incêndio e a classificação das edificações, e prescreve as tabelas de exigências das medidas de segurança contra incêndio. As IT têm como objetivo detalhar as medidas de segurança contra incêndio, especificando regras de como se implantar determinado sistema preventivo (CORPO..., 2011). O Decreto estadual $n^{\circ} 63.911$ (SÃO PAULO, 2018) também exige o cumprimento dos requisitos das normas brasileiras (NBR) e do detalhamento técnico dos projetos e instalações das medidas de segurança contra incêndio.

De acordo com Ono (2007), as regulamentações na área de segurança contra incêndio de edificações são de caráter prescritivo ou de desempenho. As regulamentações prescritivas limitam a utilização de novas soluções, apresentando requisitos específicos, como dimensões e materiais. As regulamentações de desempenho já permitem a possibilidade de utilização de novas tecnologias, atendendo às exigências do usuário em requisitos e critérios, determinando as condições de desempenho a que um material ou sistema deve atender.

Um sistema de segurança contra incêndio, conforme relata Ono (2007), é composto de um conjunto de medidas de proteção ativas e passivas. As medidas de proteção ativas têm como principais componentes iluminação de emergência, alarme de incêndio, detectores de incêndio, sinalização de emergência, extintores, hidrantes, chuveiros automáticos, outros sistemas de extinção automática de incêndio e pararaios. As medidas de proteção passivas têm como principais componentes acesso de viatura, segurança estrutural, separação entre edificações, compartimentação horizontal, compartimentação vertical, controle de materiais de acabamento, elevador de emergência, saídas de emergência e controle de fumaça. 


\section{Processo de verificação automatizada baseada em regras}

De acordo com Eastman et al. (2009), o processo de verificação automatizada baseada em regras pode ser estruturado em quatro etapas, como mostra a Figura 1.

As três primeiras etapas requerem convenções compartilhadas com relação às regras codificadas, exigindo correspondência entre as propriedades e as estruturas do modelo de construção. Para tal, pode ser necessário:

(a) que o projetista inclua explicitamente informações no modelo de construção necessário, para a verificação;

(b) que o computador extraia novos dados ou gere visões do modelo que derivem explicitamente os dados ausentes; e

(c) que algumas regras de projeto exijam simulações ou análises complexas, sendo necessária a aplicação de um modelo de análise para derivar as informações complexas e, em seguida, aplicar as regras aos dados analiticamente derivados.

Regulamentações, códigos e normas para o projeto de edifícios são definidos por pessoas e representados em linguagem humana, fazendo-se uso de textos escritos, tabelas e equações. Nos códigos de construção, essas regras têm status legal, e sua representação em um formato processável por máquina requer a interpretação e a tradução das regras escritas em código de computador. Isso é feito na etapa da interpretação das regras por meio de uma linguagem intermediária. Uma linguagem intermediária comumente aplicada nesse contexto é a lógica de predicado de primeira ordem. Segundo Eastman et al. (2009):

Na lógica, um predicado é um termo (ou função) bem definido que pode ser avaliado como VERDADEIRO ou FALSO (ou indefinido se os termos não estiverem definidos). A lógica de predicado também lida com a quantificação, se uma instrução se aplica a TODAS as instâncias em que uma condição existe ou se aplica, pelo menos, a uma das instâncias - surge a condição EXISTE.

Em edifícios, as regras normalmente são aninhadas, podendo ser gerais, aplicando-se a todo o grupo de objetos, ou replicadas para todas as ocorrências de um mesmo objeto.

Nos modelos de construção baseados em objetos, os objetos têm um tipo e propriedades. Assim, os projetistas que definem modelos de construção que serão usados para verificação de regras devem preparálos para que forneçam as informações necessárias em estruturas acordadas e bem definidas. Conhecendo-se esse preparo e o subconjunto de objetos do modelo necessários para a verificação, pode-se gerar uma visão do modelo, servido como entrada otimizada, para a verificação.

A fase de execução engloba:

(a) a verificação sintática do modelo para determinar se o modelo de construção contém as propriedades, nomes e objetos necessários para a tarefa de verificação; e

(b) um sistema, ou disciplina, de gerenciamento para coordenar e supervisionar a aplicação dos vários módulos de regras e seus resultados.

O último passo de verificação da regra, conforme Eastman et al. (2009), é relatar os resultados do projeto como parte de um teste de auditoria que valida as várias situações. As regras são definidas no âmbito da implementação, de acordo com a classe do objeto, o grupo, ou da configuração que se aplica. Sugere-se reportar o resultado da verificação graficamente por meio do mapeamento reverso da tarefa de interpretação de regras, mapeando de volta a descrição textual original da regra.

\section{Figura 1 - Etapas da verificação automatizada baseada em regras}

\begin{tabular}{llll} 
Interpretação das regras & $\begin{array}{l}\text { Preparação do } \\
\text { modelo de } \\
\text { e a estruturação lógica de } \\
\text { regras para sua aplicação }\end{array}$ & $\begin{array}{l}\text { Fase de execução } \\
\text { construção }\end{array}$ & $\begin{array}{l}\text { Relato dos } \\
\text { resultados de } \\
\text { verificação }\end{array}$ \\
\hline
\end{tabular}

Fonte: adaptada de Eastman et al. (2009). 


\section{Método}

Segundo Dresch, Lacerda e Antunes Junior (2015, p. 71), o paradigma epistemológico da pesquisa científica em projeto é a Design Science. A Design Science Research busca aproximar a teoria e a prática, com rigor, para garantir a confiabilidade dos resultados. Os objetivos da Design Science Research são:

(a) projetar e construir artefatos;

(b) prescrever soluçõos; e

(c) investigar o artefato e seu comportamento.

Os produtos da Design Science Research são artefatos que podem ser classificados em constructos, modelos, métodos, instanciações ou proposições de projeto (MARCH; SMITH, 1995). A Design Science Research é, segundo Vaishnavi, Kuechler e Petter (2019), às vezes designada como "pesquisa de melhoria", por enfatizar a natureza de resolução de problemas ou a melhoria de desempenho da atividade. Ela também é denominada por alguns de "pesquisa construtiva". Este estudo segue o delineamento da pesquisa construtiva conforme Lukka (2003), apropriando-se das fases propostas indicadas no Quadro 1.

Para examinar o potencial de investigação no setor-alvo foi aplicado um questionário com questões abertas aos representantes de cada setor para levantar como o processo é hoje realizado, se estão familiarizados com o conceito BIM e se conhecem o ferramental de automação de verificação e o potencial de aceitação de inovação nesse processo de verificação. Foram consultados na cidade de São Paulo arquitetos, engenheiros de segurança e bombeiros.

A fim de realizar a proposição da solução, adotou-se o método geral para verificação automatizada de códigos e normas de Eastman et al. (2009), desenvolvendo-se ações concatenadas de estudo das legislações federais, estaduais, municipais, normas de incêndio, da plataforma Solibri Model Checker e da ferramenta de modelagem BIM Revit Architecture. Devido à amplitude e à complexidade dos requisitos, a pesquisa foi limitada à formulação de uma solução para verificação de regras sobre um contexto específico e com potencial social. Dessa forma, destacou-se a habitação de interesse social verticalizada. Essa proposição deuse pelo mapeamento dos componentes de verificação de projeto identificados nas legislações, normas e recursos existentes de regras, parametrizações e composições.

\section{Quadro 1 - Detalhamento do delineamento adotado}

\begin{tabular}{|l|l|}
\hline \multicolumn{1}{|c|}{ Fase } & \multicolumn{1}{c|}{ Detalhamento } \\
\hline $\begin{array}{l}\text { Examinar o potencial de } \\
\text { investigação no setor- } \\
\text { alvo }\end{array}$ & $\begin{array}{l}\text { Definir o potencial de absorção da verificação automatizada de normas } \\
\text { em projeto com BIM no setor-alvo (construtoras, engenheiros, } \\
\text { arquitetos, bombeiros e agências normativas). }\end{array}$ \\
\hline $\begin{array}{l}\text { Obter conhecimento } \\
\text { geral e profundo do tema }\end{array}$ & $\begin{array}{l}\text { Fundamentação teórica: leis e regulamentações de segurança contra } \\
\text { incêndio em edifícios de uso residencial privativo multifamiliar \& } \\
\text { Método para verificação automatizada de códigos e normas de Eastman } \\
\text { et al. } \text { (2009). }\end{array}$ \\
\hline $\begin{array}{l}\text { Propor uma solução } \\
\text { inovadora e desenvolver } \\
\text { uma construção que } \\
\text { solucione um problema } \\
\text { real }\end{array}$ & $\begin{array}{l}\text { Formulação da solução: definição das medidas de segurança contra } \\
\text { incêndio, identificação dos objetos no modelo associado a requisitos } \\
\text { das regulamentaçôes. }\end{array}$ \\
\hline $\begin{array}{l}\text { Implementar a solução e } \\
\text { testar }\end{array}$ & $\begin{array}{l}\text { Definição e parametrização das regras e teste com casos positivos e } \\
\text { negativos. }\end{array}$ \\
\hline $\begin{array}{l}\text { Refletir sobre a } \\
\text { aplicabilidade }\end{array}$ & $\begin{array}{l}\text { Avaliar o alinhamento da solução segundo o método de Eastman } \text { et al. } \\
\text { (2009). }\end{array}$ \\
\hline $\begin{array}{l}\text { Identificar e analisar as } \\
\text { contribuições teóricas }\end{array}$ & $\begin{array}{l}\text { Discussão prática considerando o potencial de generalização da } \\
\text { solução e limitações (impactos, posicionamentos e mudanças). }\end{array}$ \\
\hline
\end{tabular}


Nesta pesquisa operacionalizaram-se as regras da norma de segurança contra incêndio pertinente à edificação residencial multifamiliar na plataforma Solibri Model Checker v9.5. O caso selecionado para teste foi o já estudado pelos Grupos de Pesquisa Grupos de Pesquisa Modelagem da Informação e Colaboração Digital na Arquitetura, Engenharia e Construção ${ }^{1}$ (GMIC) e Humanizar o Habitar e a Cidade ${ }^{2}$ (Habitares). Trata-se de um conjunto habitacional composto de prédios em formato " $\mathrm{H}$ " de cinco andares para habitação de interesse social, padrão amplamente construído pela Companhia de Desenvolvimento Habitacional e Urbano (CDHU) no estado de São Paulo. Partiu-se da modelagem já realizada pelo grupo na ferramenta Revit Architecture v2016. Dessa forma, o artefato resultante desta pesquisa construtiva é a instanciação. Para March e Smith (1995), instanciações operacionalizam outros artefatos, como construções, modelos e métodos. A operacionalização visa principalmente demonstrar a viabilidade e a eficácia dos artefatos construídos.

Para testar o funcionamento da solução implementada no Solibri Model Checker foram desenvolvidos dois casos-testes a partir do modelo original. O caso-teste positivo acrescentou ao projeto de partida componentes para segurança contra incêndio. $\mathrm{O}$ caso-teste negativo continha falhas de projeto de segurança contra incêndio (componentes ausentes ou incorretos, propriedades ausentes ou incorretas). A solução era executada sobre os dois casos buscando-se a aprovação do requisito em questão ou a identificação do não atendimento.

A aplicabilidade da solução foi avaliada nos contextos interno e externo. A reflexão interna verificou o alinhamento da solução de acordo com a estruturação de Eastman et al. (2009), isto é, interpretação das regras e estruturação lógica, preparação do modelo, execução das regras e relato dos resultados. Buscou-se avaliar o quanto o modelo de informação teve de ser adaptado ou transformado para viabilizar seu uso nesse processo, e se o modelo de informação ou os recursos do Solibri Model Checker foram razão de restrições no processo de automatização. Buscou-se também identificar como orientar os usuários para a utilização da proposta. A reflexão externa envolveu identificar a percentagem da norma que o conjunto de regras desenvolvido abrangia e avaliar o potencial da solução desenvolvida. Também foi avaliada a diferenciação ou complementação desta pesquisa diante dos trabalhos correlatos brasileiros.

\section{Resultados}

\section{Potencial da pesquisa no setor-alvo}

Foi realizado um levantamento com profissionais da área de segurança contra incêndio situados na cidade de São Paulo, entre eles engenheiros, arquitetos e bombeiros vinculados a órgãos públicos ou entidades privadas (KATER; RUSCHEL, 2014). Verificou-se que a grande maioria realiza a verificação manual com o apoio do ferramental de Computer Aided Design (CAD), e ainda existe uma porção pequena de profissionais que realizam a verificação estritamente no formato manual. Este estudo apontou que a grande maioria dos profissionais de segurança desconhece BIM, fato que pode se tornar uma potencial barreira para a adoção da verificação automatizada de códigos nesse setor. Porém, quando questionados se fariam uso desse recurso, a totalidade demonstrou receptividade. Dessa forma, apesar da potencial barreira em se adotar o BIM na verificação de projeto em segurança contra incêndio pela falta de conhecimento da tecnologia, o interesse pelo aprimoramento e melhoramento do desempenho dessa verificação pode ser um vetor de transposição.

\section{Formulação da solução}

A elaboração das regras teve como base uma seleção objetiva dos requisitos das regulamentações de incêndio. De acordo com o Decreto estadual n ${ }^{\circ}$ 63.911 (SÃO PAULO, 2018), o caso selecionado é caracterizado como edificação residencial do Grupo A, Divisão A-2, descrito como habitação multifamiliar com altura "H" entre 6 m e 12 m, classificada como edificação do tipo III. O Quadro 2 destaca as medidas de segurança contra incêndio para o caso em questão. Com essa definição foi possível identificar as IT e normas relacionadas (Figura 2).

Para cada uma das medidas identificaram-se as regulamentações, os componentes de projeto, consequentemente os objetos no modelo de informação, e os requisitos de parametrização. Um exemplo é demonstrado no Quadro 3.

1http://dgp.cnpq.br/dgp/espelhogrupo/3341775055603418.

${ }^{2}$ http://dgp.cnpq.br/dgp/espelhogrupo/5719405265474942. 
Quadro 2 - Medidas de segurança contra incêndio aplicáveis a edificações do Grupo A com área superior a $750 \mathrm{~m}^{2}$ ou altura superior a $12 \mathrm{~m}$

\begin{tabular}{|c|c|c|c|c|c|c|}
\hline Grupo de ocupação e uso & \multicolumn{6}{|c|}{ GRUPO A - RESIDENCIAL } \\
\hline Divisão & \multicolumn{6}{|c|}{ A-2, A-3 e condomínios residenciais } \\
\hline \multirow{2}{*}{$\begin{array}{c}\text { Medidas de segurança } \\
\text { contra incêndio }\end{array}$} & \multicolumn{6}{|c|}{ Classificação quanto à altura (em metros) } \\
\hline & Térrea & $H \leq 6$ & $6<\mathrm{H} \leq 12$ & $12<\mathrm{H} \leq 23$ & $\mathbf{2 3}<\mathbf{H} \leq \mathbf{3 0}$ & Acima de 30 \\
\hline $\begin{array}{c}\text { Acesso de viatura na } \\
\text { edificação }\end{array}$ & $X$ & $X$ & $X$ & $X$ & $X$ & $X$ \\
\hline $\begin{array}{l}\text { Segurança estrutural contra } \\
\text { incêndio }\end{array}$ & $X$ & $X$ & $X$ & $\mathrm{X}$ & $\mathrm{X}$ & $X$ \\
\hline Compartimentação vertical & - & - & - & $\mathrm{X}^{2}$ & $\mathrm{X}^{2}$ & $\mathrm{X}^{2}$ \\
\hline $\begin{array}{l}\text { Controle de materiais de } \\
\text { acabamento }\end{array}$ & - & - & - & $X$ & $X$ & $\mathrm{X}$ \\
\hline Saídas de emergência & $\mathrm{X}$ & $\mathrm{X}$ & $\mathrm{X}$ & $\mathrm{X}$ & $\mathrm{X}$ & $\mathrm{X}^{1}$ \\
\hline Brigada de incêndio & $\mathrm{X}$ & $\mathrm{X}$ & $\mathrm{X}$ & $\mathrm{X}$ & $\mathrm{X}$ & $\mathrm{X}$ \\
\hline Iluminação de emergência & $\mathrm{X}$ & $\mathrm{X}$ & $\mathrm{X}$ & $\mathrm{X}$ & $\mathrm{X}$ & $\mathrm{X}$ \\
\hline Alarme de incêndio & $\mathrm{X}^{3}$ & $\mathrm{X}^{3}$ & $\mathrm{X}^{3}$ & $\mathrm{X}^{3}$ & $\mathrm{X}^{3}$ & $\mathrm{X}$ \\
\hline Sinalização de emergência & $\mathrm{X}$ & $\mathrm{X}$ & $\mathrm{X}$ & $\mathrm{X}$ & $\mathrm{X}$ & $\mathrm{X}$ \\
\hline Extintores & $\mathrm{X}$ & $\mathrm{X}$ & $\mathrm{X}$ & $\mathrm{X}$ & $\mathrm{X}$ & $\mathrm{X}$ \\
\hline Hidrante e mangotinhos & $\mathrm{X}$ & $\mathrm{X}$ & $\mathrm{X}$ & $\mathrm{X}$ & $\mathrm{X}$ & $\mathrm{X}$ \\
\hline
\end{tabular}

Fonte: São Paulo (2018).

Notas: 1 - Deve haver elevador de emergência para altura maior que $80 \mathrm{~m}$. 2 - Pode ser substituída por sistema de controle de fumaça somente nos átrios. 3 - Pode ser substituído pelo sistema de interfone, desde que cada apartamento possua um ramal ligado à central, que deve ficar numa portaria com vigilância humana $24 \mathrm{~h}$ e tenha fonte autônoma com duração de $60 \mathrm{~min}$. 
Figura 2 - Levantamento das instruções técnicas e normas associadas às medidas de segurança contra incêndio

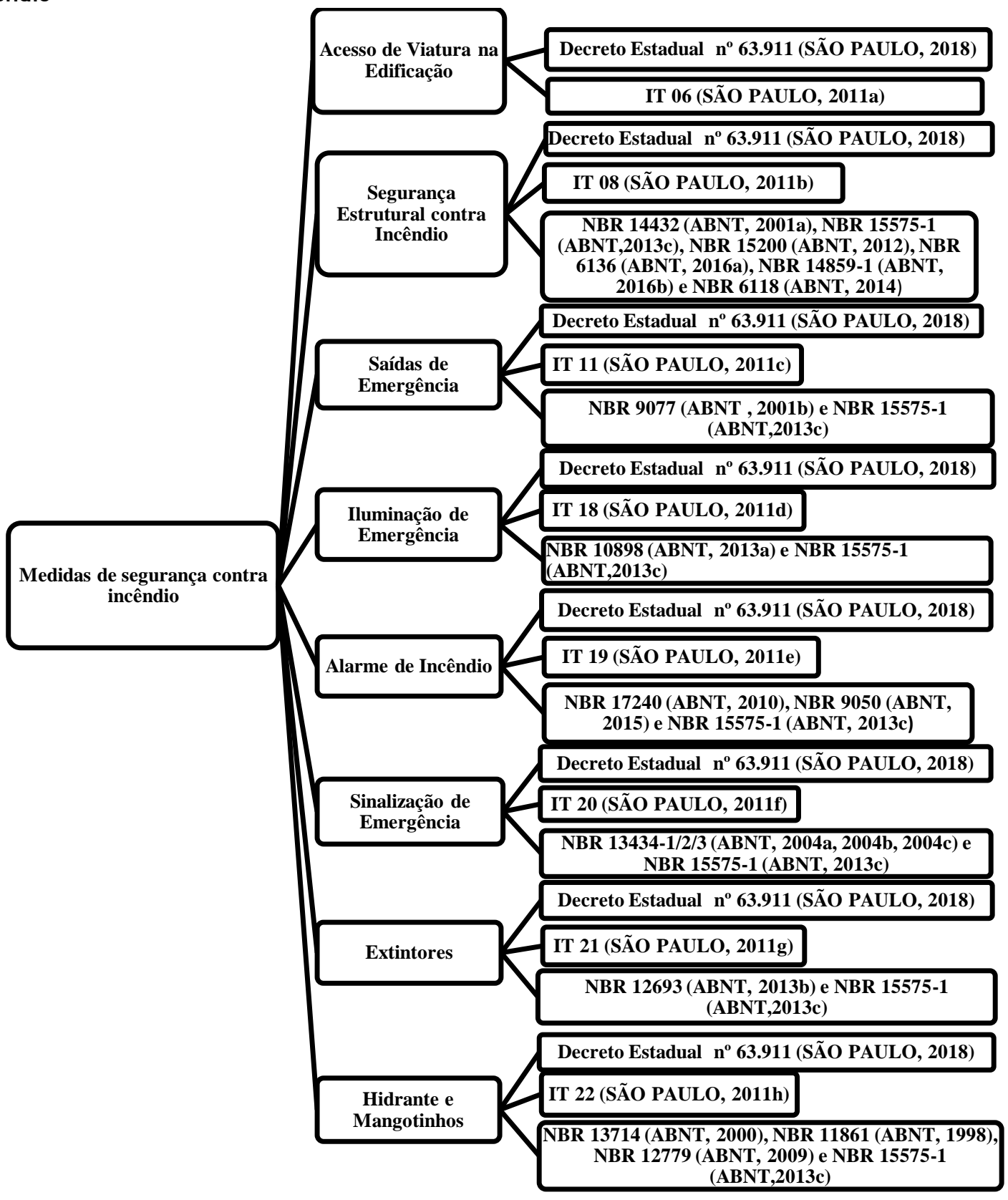

Quadro 3 - Objetos no modelo e requisitos para a medida de segurança relativa a extintores de edificações no Grupo A - Residencial

\begin{tabular}{|l|l|}
\hline Objeto no modelo & \multicolumn{1}{c|}{ REQUISITOS } \\
\hline \multirow{5}{*}{ Extintor } & Quantidade mínima de extintores por pavimento: dois extintores \\
\cline { 2 - 2 } & Tipo de instalação: portátil \\
\cline { 2 - 2 } & Tipo de extintor: $\mathrm{H}_{2} \mathrm{O}$, pó químico \\
\cline { 2 - 2 } & Capacidade extintora mínima: $2 \mathrm{~A}, 20-\mathrm{B}: \mathrm{C}$ \\
\cline { 2 - 2 } & Material: aço \\
\cline { 2 - 2 } & Altura máxima até o topo do extintor: $1,60 \mathrm{~m}$ \\
\cline { 2 - 2 } & Altura mínima até a base do extintor: $0,10 \mathrm{~m}$ \\
\hline
\end{tabular}

Fonte: São Paulo (2018, 2011h) e ABNT (2013b, 2013c). 


\section{Implementação e teste da solução}

O Solibri Model Checker v.9.5 tem uma biblioteca de regras denominadas SOL. As regras desenvolvidas para representar as medidas de segurança podem ser derivadas simples das regras SOL ou compostas de múltiplas derivações de regras SOL, determinando um conjunto de regras (ruleset). A estratégia geral criada para o mapeamento dos requisitos das medidas de segurança em regras SOL do Solibri Model Checker é apresentada no Quadro 4. O Quadro 5 enumera as regras desenvolvidas indicando as medidas correspondentes, o tipo de estratégia utilizado, os requisitos parametrizados e os componentes do modelo BIM envolvidos. Podem-se observar casos de mapeamento duplo, isto é, requisitos que poderiam ser representados em regras SOL seguindo a estratégia 1, mas que, com maior esforço de parametrização, também poderiam ser representados pela estratégia 2. Observa-se dessa forma que existe mais de uma maneira de implementar uma medida de segurança. A medida de segurança relativa à brigada de incêndio não foi implementada, pois não é relativa ao projeto. Observa-se que houve, para as 11 regras desenvolvidas, 20 utilizações de regras SOL e 60 parametrizações.

Quadro 4 - Estratégias adotadas para seleção de regras no Solibri Model Checker

\begin{tabular}{|l|l|}
\hline \multicolumn{1}{|c|}{ Identificação } & \multicolumn{1}{c|}{ Descrição da estratégia. } \\
\hline $\begin{array}{l}\text { Estratégia 1 } \\
\text { (específica) }\end{array}$ & $\begin{array}{l}\text { Se existir uma regra para o contexto específico, então utilizar a } \\
\text { regra específica. }\end{array}$ \\
\hline $\begin{array}{l}\text { Estratégia 2 } \\
\text { (geral) }\end{array}$ & $\begin{array}{l}\text { Se não existir uma regra específica, mas existir uma geral } \\
\text { ajustável, então utilizar a regra geral. }\end{array}$ \\
\hline $\begin{array}{l}\text { Estratégia 3 } \\
\text { (adaptação) }\end{array}$ & $\begin{array}{l}\text { Se não existir uma regra específica, nem uma geral aplicável, } \\
\text { mas existir uma regra específica adaptável, então utilizar a } \\
\text { regra fora de contexto adaptando-a ao contexto em questão. }\end{array}$ \\
\hline
\end{tabular}

Fonte: Kater e Ruschel (2018, p. 3245).

Quadro 5 - Resumo das regras derivadas simples do Solibri Model Checker (Continua...)

\begin{tabular}{|c|c|c|c|c|c|c|}
\hline \multirow{2}{*}{ Regra } & \multirow{2}{*}{ Medidas } & \multicolumn{3}{|c|}{ Regras SOL } & \multirow{2}{*}{$\begin{array}{l}\text { Predicado } \\
\text { Requisitos } \\
\end{array}$} & \multirow{2}{*}{$\begin{array}{c}\text { Componentes do } \\
\text { modelo BIM }\end{array}$} \\
\hline & & E1 & E2 & E3 & & \\
\hline 01 & $\begin{array}{l}\text { Classificação } \\
\text { quanto à altura } \\
\text { (em metros) }\end{array}$ & & 230 & & $\begin{array}{l}\text { 1. a altura mínima da } \\
\text { edificação }\end{array}$ & Laje e level \\
\hline 02 & $\begin{array}{l}\text { Edificações do } \\
\text { Grupo A com } \\
\text { área superior a } \\
750 \mathrm{~m}^{2}\end{array}$ & & 230 & & $\begin{array}{l}\text { 2. a área mínima da } \\
\text { edificação }\end{array}$ & Laje, level e room \\
\hline 03 & $\begin{array}{l}\text { Classificação } \\
\text { quanto à altura } \\
\text { (em metros) }\end{array}$ & $220 *$ & 230 & & \begin{tabular}{|l} 
3. \\
o intervalo entre as \\
alturas mínima e \\
máxima da edificação
\end{tabular} & Laje, level \\
\hline 04 & $\begin{array}{l}\text { Acesso de } \\
\text { viatura na } \\
\text { edificação }\end{array}$ & $222 *$ & 230 & & $\begin{array}{l}\text { 4. a largura mínima da via } \\
\text { de acesso da viatura }\end{array}$ & $\begin{array}{l}\text { Calçada, level e } \\
\text { room }\end{array}$ \\
\hline 05 & $\begin{array}{l}\text { Segurança } \\
\text { estrutural } \\
\text { contra incêndio }\end{array}$ & & 230 & & 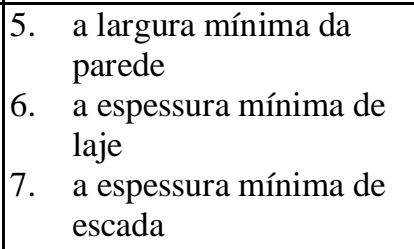 & $\begin{array}{l}\text { Parede, laje e } \\
\text { escada }\end{array}$ \\
\hline $\mathrm{E}$ & $\begin{array}{l}\text { atégia escolhid } \\
\text { ratégia } 1 \text { para } \\
\text { ratégia } 2 \text { para } \\
\text { ratégia } 3 \text { para }\end{array}$ & a & c & & & \\
\hline
\end{tabular}


Quadro 5 - Resumo das regras derivadas compostas do Solibri Model Checker (continuação)

\begin{tabular}{|c|c|c|c|c|c|c|}
\hline \multirow{2}{*}{ Regra } & \multirow{2}{*}{ Medidas } & \multicolumn{3}{|c|}{ Regras SOL } & \multirow{2}{*}{$\begin{array}{l}\text { Predicado } \\
\text { Requisitos }\end{array}$} & \multirow{2}{*}{$\begin{array}{l}\text { Componentes do } \\
\text { modelo BIM }\end{array}$} \\
\hline & & E1 & E2 & E3 & & \\
\hline \multirow{3}{*}{06} & \multirow{3}{*}{$\begin{array}{l}\text { Saídas de } \\
\text { emergência }\end{array}$} & $179 *$ & 230 & & $\begin{array}{l}\text { 8. a rota de fuga da edificação } \\
\text { 9. a largura mínima para acesso, } \\
\text { escadas e descargas } \\
\text { 10. o pé-direito mínimo para } \\
\text { acesso, escadas e descargas }\end{array}$ & $\begin{array}{l}\text { Laje, parede, } \\
\text { escada, level, } \\
\text { room e porta }\end{array}$ \\
\hline & & $210 *$ & 230 & & $\begin{array}{l}\text { 11. a largura da escada } \\
\text { 12. a largura do degrau da escada } \\
\text { 13. a altura do degrau da escada }\end{array}$ & Escada \\
\hline & & $210 *$ & 230 & & $\begin{array}{l}\text { 14. o material da escada } \\
\text { 15. o material do corrimão } \\
\text { 16. a dimensão do corrimão } \\
\text { 17. a distância do corrimão até o } \\
\text { piso }\end{array}$ & $\begin{array}{l}\text { Escada, corrimão, } \\
\text { level e laje }\end{array}$ \\
\hline \multirow[t]{2}{*}{07} & \multirow[t]{2}{*}{$\begin{array}{l}\text { Iluminação } \\
\text { de } \\
\text { emergência }\end{array}$} & & 230 & & $\begin{array}{l}\text { 18. o tipo de sistema da } \\
\text { iluminação } \\
\text { 19. o tipo de iluminação de } \\
\text { emergência } \\
\text { 20. o material da luminária } \\
\text { 21. o tipo de lâmpada } \\
\text { 22. a autonomia mínima da } \\
\text { iluminação } \\
\text { 23. o nível mínimo de } \\
\text { iluminamento }\end{array}$ & Luminária \\
\hline & & & 231 & & $\begin{array}{l}\text { 24. o número mínimo de } \\
\text { luminárias por pavimento }\end{array}$ & Luminária \\
\hline \multirow{2}{*}{08} & \multirow{2}{*}{$\begin{array}{l}\text { Alarme de } \\
\text { Incêndio }\end{array}$} & & 230 & & $\begin{array}{l}\text { 25. a altura máxima do piso ao } \\
\text { topo do interfone } \\
\text { 26. o material do interfone }\end{array}$ & Interfone \\
\hline & & & 231 & & $\begin{array}{l}\text { 27. o número mínimo de } \\
\text { interfones por pavimento }\end{array}$ & Interfone \\
\hline \multirow[t]{2}{*}{09} & \multirow[t]{2}{*}{$\begin{array}{l}\text { Sinalização } \\
\text { de } \\
\text { emergência }\end{array}$} & & 230 & & $\begin{array}{l}\text { 28. a altura do piso até a base da } \\
\text { sinalização } \\
\text { 29. o comprimento mínimo da } \\
\text { placa de sinalização } \\
\text { 30. a altura mínima da placa de } \\
\text { sinalização } \\
\text { 31. o material da placa de } \\
\text { sinalização } \\
\text { 32. o nome da sinalização }\end{array}$ & Sinalização \\
\hline & & & 231 & & $\begin{array}{l}\text { 33. o número mínimo de } \\
\text { sinalizações por pavimento }\end{array}$ & Sinalização \\
\hline
\end{tabular}

Nota: Legenda:

*: estratégia escolhida;

E1: estratégia 1 para escolha de regra SOL;

E2: estratégia 2 para escolha de regra SOL; e

E3: estratégia 3 para escolha de regra SOL. 
Quadro 5 - Resumo das regras derivadas compostas do Solibri Model Checker (continuação)

\begin{tabular}{|c|c|c|c|c|c|c|}
\hline \multirow{2}{*}{ Regra } & \multirow{2}{*}{ Medidas } & \multicolumn{3}{|c|}{ Regras SOL } & \multirow{2}{*}{\begin{tabular}{|l|} 
Predicado \\
Requisitos
\end{tabular}} & \multirow{2}{*}{$\begin{array}{c}\text { Componentes do } \\
\text { modelo BIM }\end{array}$} \\
\hline & & E1 & E2 & E3 & & \\
\hline \multirow[t]{2}{*}{10} & \multirow[t]{2}{*}{ Extintores } & & 230 & & $\begin{array}{l}\text { 34. o tipo de instalação do } \\
\text { extintor } \\
\text { 35. o tipo de extintor } \\
\text { 36. a capacidade extintora } \\
\text { 37. o material do extintor } \\
\text { 38. a altura máxima do extintor } \\
\text { 39. a altura mínima do extintor }\end{array}$ & Extintor \\
\hline & & & 231 & & $\begin{array}{l}\text { 40. o número mínimo de } \\
\text { extintores por pavimento }\end{array}$ & Extintor \\
\hline \multirow{4}{*}{11} & \multirow{4}{*}{$\begin{array}{l}\text { Hidrante e } \\
\text { mangotinhos }\end{array}$} & & & 161 & $\begin{array}{l}\text { 41. o comprimento da mangueira } \\
\text { do hidrante } \\
\text { 42. a distância de objetos ao } \\
\text { hidrante }\end{array}$ & $\begin{array}{l}\text { Hidrante, parede, } \\
\text { escada, level, } \\
\text { room e porta }\end{array}$ \\
\hline & & 222 & 230 & & $\begin{array}{l}\text { 43. a posição central do hidrante } \\
\text { até os objetos } \\
\text { 44. a distância entre o dispositivo } \\
\text { de recalque e a guia } \\
\text { 45. a distância da parede acabada } \\
\text { até a face lateral do hidrante }\end{array}$ & $\begin{array}{l}\text { Hidrante, escada, } \\
\text { porta e } \\
\text { dispositivo de } \\
\text { recalque, level, } \\
\text { room e passeio }\end{array}$ \\
\hline & & & 230 & & $\begin{array}{l}\text { 46. a classificação do sistema do } \\
\text { hidrante } \\
\text { 47. o material do abrigo do } \\
\text { hidrante } \\
\text { 48. o material do esguicho do } \\
\text { hidrante } \\
\text { 49. a vazão do esguicho } \\
\text { 50. o material da mangueira do } \\
\text { hidrante } \\
\text { 51. a largura do abrigo do } \\
\text { hidrante } \\
\text { 52. o comprimento do abrigo do } \\
\text { hidrante } \\
\text { 53. a altura do abrigo do hidrante } \\
\text { 54. o diâmetro da mangueira do } \\
\text { hidrante } \\
\text { 55. a altura mínima do abrigo do } \\
\text { hidrante } \\
\text { 56. a altura máxima do abrigo do } \\
\text { hidrante } \\
\text { 57. o comprimento da tampa do } \\
\text { dispositivo de recalque } \\
\text { 58. a altura da tampa do } \\
\text { dispositivo de recalque } \\
\text { 59. o material da tampa do } \\
\text { dispositivo de recalque }\end{array}$ & $\begin{array}{l}\text { Hidrante, } \\
\text { dispositivo de } \\
\text { recalque, level, } \\
\text { room e tampa do } \\
\text { dispositivo de } \\
\text { recalque }\end{array}$ \\
\hline & & & 231 & & $\begin{array}{l}\text { 60. o número mínimo de } \\
\text { hidrantes por pavimento }\end{array}$ & Hidrante \\
\hline
\end{tabular}

Nota: Legenda:

*: estratégia escolhida;

E1: estratégia 1 para escolha de regra SOL;

E2: estratégia 2 para escolha de regra SOL; e

E3: estratégia 3 para escolha de regra SOL. 
Foram desenvolvidos dois casos-testes a partir do modelo BIM. O caso-teste positivo acrescentou ao projeto original componentes para segurança contra incêndio. Na Figura 3 (superior) observa-se o acréscimo dos objetos de sinalização de emergência, como sinalização do extintor de pó químico, sinalização da saída de emergência, sinalização do extintor de $\mathrm{H}_{2} \mathrm{O}$ e sinalização do hidrante. $\mathrm{O}$ caso-teste negativo continha falhas de projeto de segurança contra incêndio (componentes ausentes ou incorretos, propriedades ausentes ou incorretas). Na Figura 5 (inferior) observam-se as seguintes falhas: o termo "Wrong value of PropertyBottom Elevation: 2.10 m" indica que a altura do piso até a base da placa de sinalização de emergência foi de 2,10 m, o que está em desacordo com o valor parametrizado de $1,8 \mathrm{~m}$; o termo "Wrong value of Property-Dimension. Comprimento: $150 \mathrm{~mm}$ " indica que o comprimento da placa de sinalização foi de 150 $\mathrm{mm}$, o que está em desacordo com o valor parametrizado de igual ou maior que $180 \mathrm{~mm}$; o termo "Wrong value of Property-Material. Madeira: MDF" indica que o material da placa foi MDF, o que está em desacordo com o valor parametrizado, PVC vermelho. A solução era executada sobre os dois casos, buscando-se a aprovação do requisito em questão ou a identificação do não atendimento a ele. Esse teste se repetiu para todas as regras desenvolvidas.

Figura 3 - Resultado da verificação de sinalização de emergência sobre o caso-teste positivo (acima) e sobre o caso-teste negativo (abaixo)
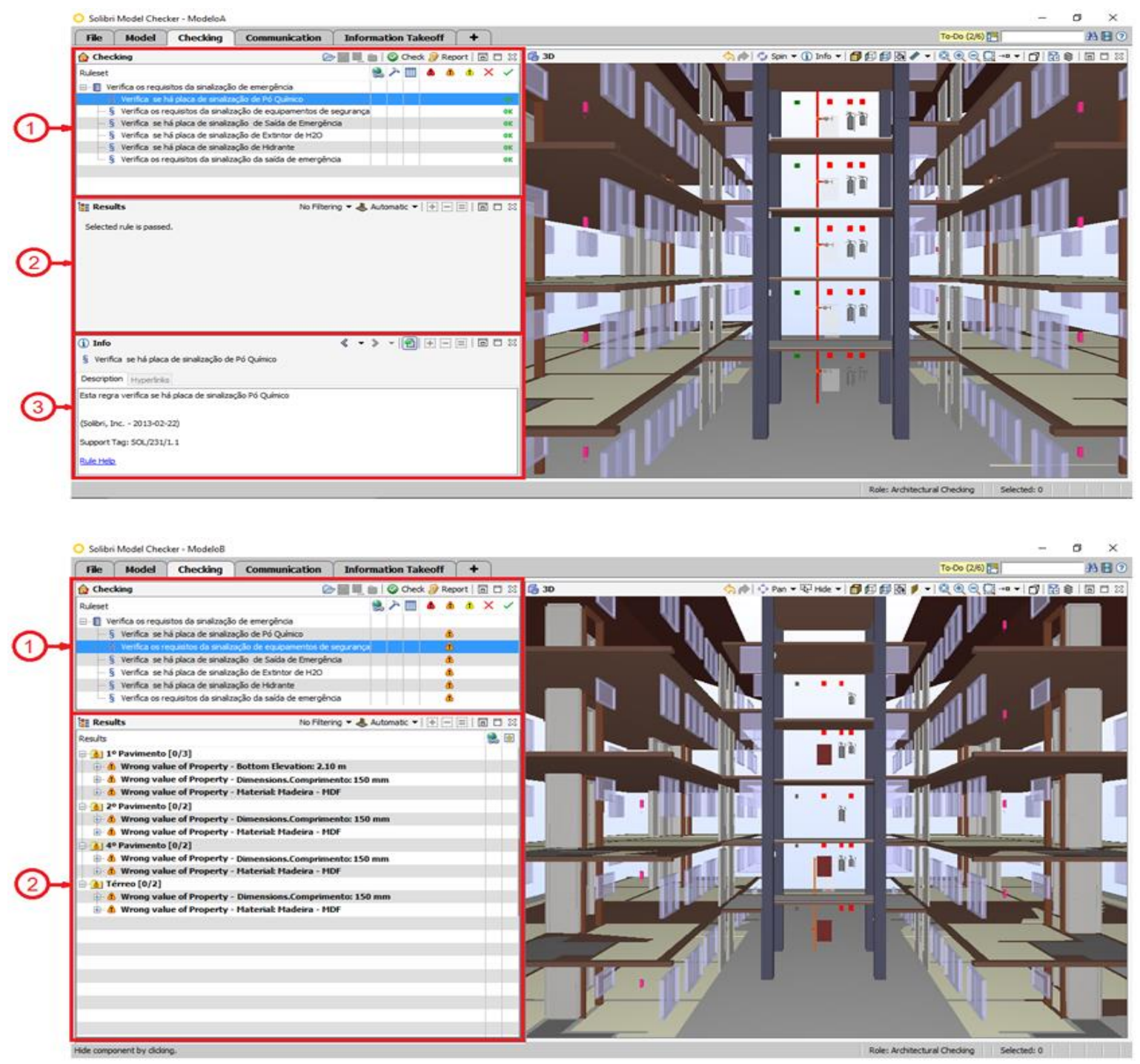

Fonte: Kater e Ruschel (2018, p. 3248). 


\section{Avaliação da aplicabilidade}

Foi verificado o alinhamento da solução com as etapas de verificação por regras proposta por Eastman et al. (2009). Essas etapas são a interpretação das regras e sua estruturação lógica, a preparação do modelo de construção, a execução das regras e o relato de verificação.

\section{A interpretação das regras e sua estruturação lógica}

A interpretação das regras partiu do Decreto estadual no 63.911 (SÃO PAULO, 2018), que regulamenta a segurança contra incêndio em edificações, ao qual se aplicou um recorte para o desenvolvimento de regras, guiado pelo tipo da edificação e sua tipologia. A tipologia foi considerada em sua totalidade, isto é, um prédio em forma de "H" compreendendo dois blocos de apartamentos interligados pela circulação vertical. Essa premissa estabeleceu a área total da edificação em análise, determinando a classificação da edificação (Quadro 2).

A estruturação lógica das regras é apresentada na Figura 4. O processo de implementação das regras no Solibri Model Checker resultou no conjunto de regras apresentado no Quadro 5. Na Figura 5 observa-se a porcentagem de utilização de cada regra empregada entre as 20 utilizações, considerando as repetições nas parametrizações associadas. Observa-se maior frequência de utilização da SOL/230, consequentemente da estratégia 2 de escolha de regras, pois oferece um esquema generalizado e parametrizável de verificação de propriedades de um componente por meio de filtros.

Realizando a análise de alinhamento com o método para verificação automatizada de códigos e normas de Eastman et al. (2009), nota-se coerência com a fase de interpretação de regras e estruturação lógica proposta no método. A lógica de predicado é aplicada na parametrização dos requisitos (Quadro 5). Verifica-se hierarquia entre as regras, que será explicada adiante.

\section{Figura 4 - Sequência de interpretação das regras e a estruturação lógica para sua parametrização}

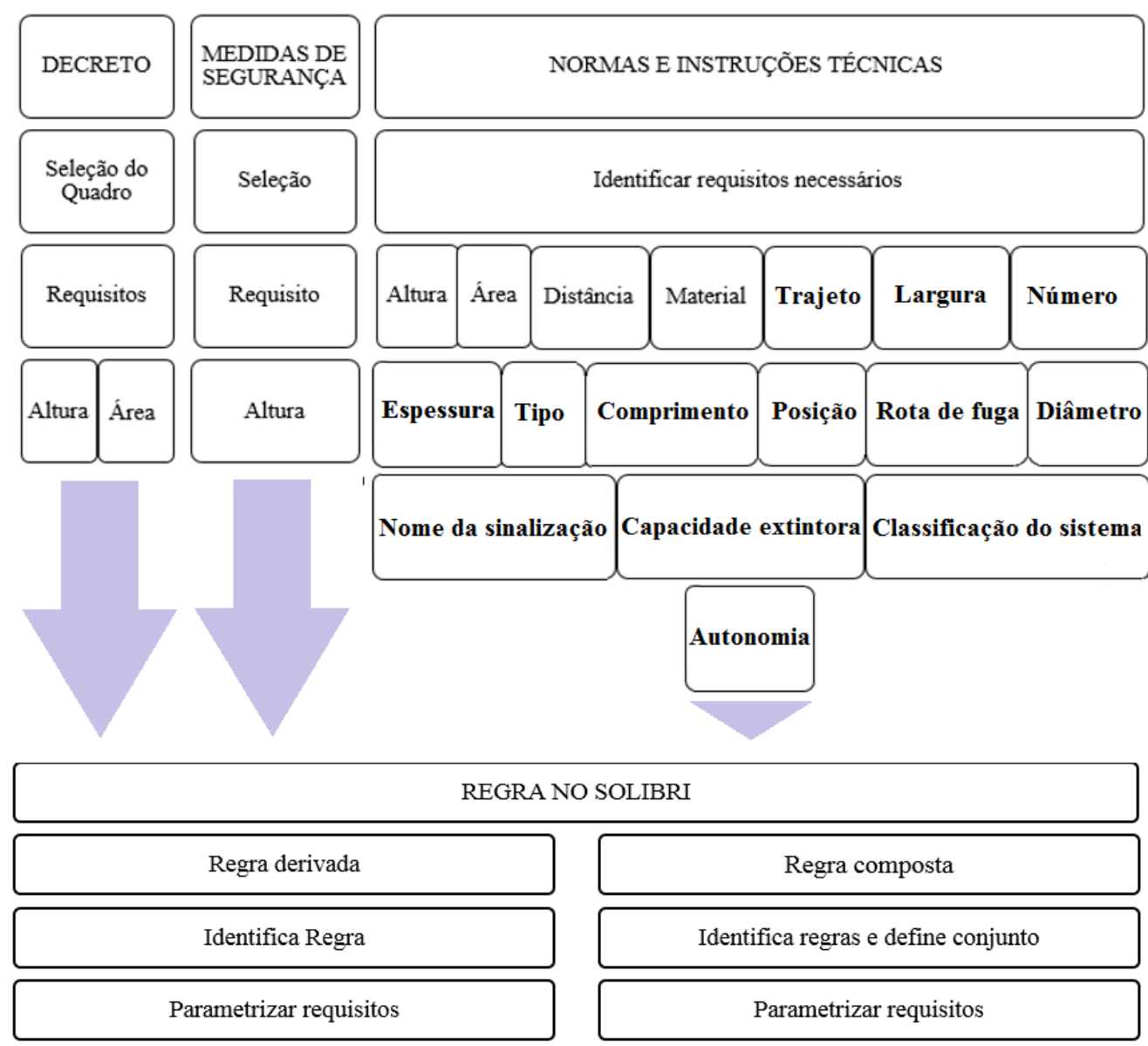

Fonte: Kater e Ruschel (2018, p. 3247). 
Figura 5 - Frequência das regras utilizadas pelo Solibri Model Checker

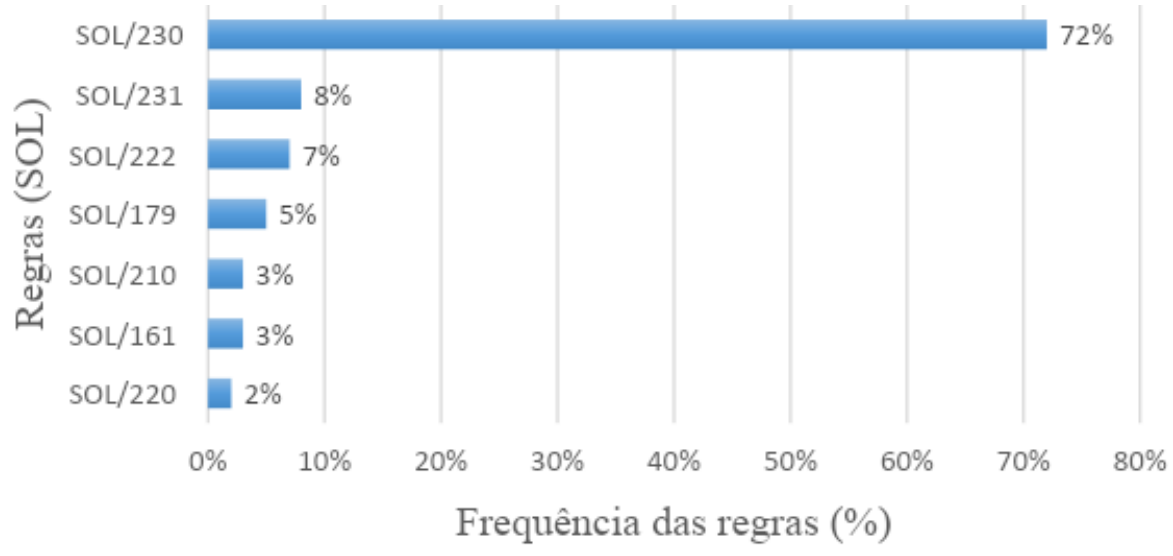

\section{Preparação do modelo de construção}

O aplicativo Revit Architecture possibilitou a modelagem de arquitetura, estruturas e instalações no mesmo ambiente, onde se utiliza o conceito de família para organizar os objetos. As famílias utilizadas para a modelagem na elaboração de um projeto de segurança contra incêndio foram famílias do sistema, famílias carregáveis e famílias locais. As famílias do sistema utilizadas foram Level, Room, Tag Room, Wall, Door, Floor, Stair e Railing. As famílias carregáveis são criadas em arquivos RFA externos, importadas e modificadas. Para este projeto importou-se o arquivo Bracket_Mounted_Fire_Extinguishe.rfa. As famílias locais são aquelas com objetos criados dentro do arquivo do projeto. Com este último recurso foram criadas a famílias locais Iluminação.rfa, Interfone.rfa, SinalizaçãoHidrandte.rfa, SinalizaçãoPóQuímico.rfa, SinalizaçãoH2O.rfa, SinalizaçãoSaídaEmergência.rfa e Hidrante.rfa.

Neste estudo, a elaboração do projeto de segurança contra incêndio no aplicativo Revit Architecture se deu com o uso do modelo BIM do conjunto habitacional em estudo. O modelo BIM foi desenvolvido pelo grupo de pesquisa a partir do projeto básico fornecido pelo CDHU de uma edificação em formato " $\mathrm{H}$ " de cinco andares. Esse modelo foi parametrizado com requisitos dentro dos limites exigidos pelas regulamentações. A Figura 6 exemplifica o modelo BIM da edificação, destacando exclusivamente os objetos utilizados nas regras para a verificação das medidas de segurança contra incêndio. Os objetos utilizados foram laje, escada, corrimão, extintor, hidrante, sinalização, esguicho, mangueira, abrigo do hidrante, iluminação de emergência, dispositivos de recalque, interfone, passeio, alvenaria e portas. Nota-se que somente um subconjunto de objetos do modelo, com um subconjunto de propriedades, é necessário para o processo de verificação automatizada. Isso indica que é possível criar futuramente uma extração de Model View Definition (MVD) específica e otimizada para essa tarefa. A Figura 9 e o Quadro 5 indicam os objetos e propriedades necessários para a composição de um MVD específico. Foram descartados os objetos telhado, janelas, tubulações elétrica e hidráulica, louças e revestimentos. O Quadro 6 indica um resumo da preparação e parametrização do modelo. A finalização da modelagem se deu com a exportação do arquivo para o esquema IFC.

Realizando a análise de alinhamento com o método para verificação automatizada de códigos e normas de Eastman et al. (2009), nota-se coerência com a fase de preparação do modelo como proposta no método. Das 11 regras criadas, 5 exigiram preparação do modelo (45\%). Essa preparação viabilizou maior alcance da automação da verificação sobre o conjunto de medidas de segurança, demonstrando ser inviável utilizar um modelo sem preparação para o processo de verificação. 
Figura 6 - Detalhe dos objetos utilizados nas regras de verificação das medidas de segurança contra incêndio
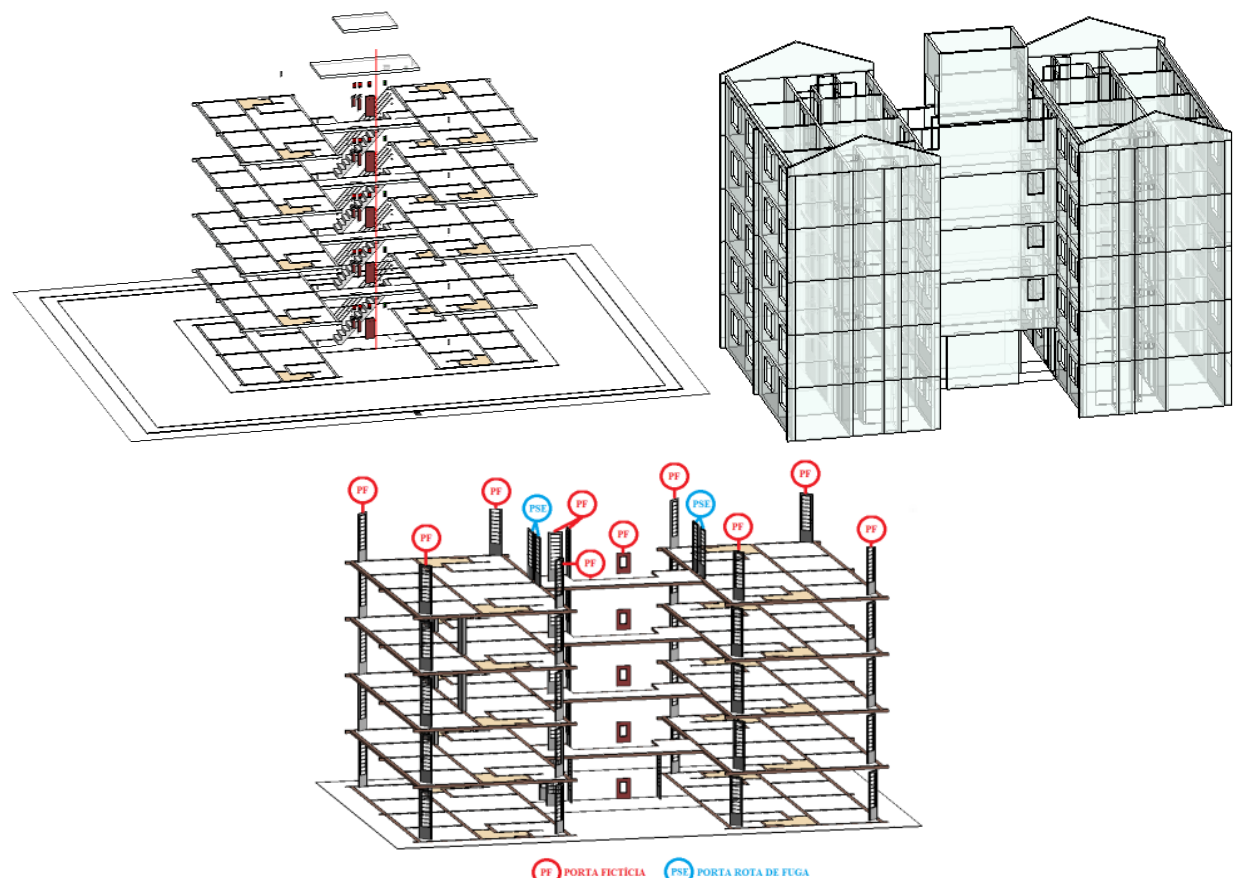

Nota:

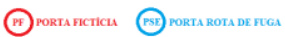

à esquerda: lajes, escadas, corrimão, extintor, hidrante, sinalização, iluminação, dispositivo de recalque e passeio; ao centro: alvenaria; e

à direita: portas utilizadas nas regras de distância percorrida.

Quadro 7 - Ações de modelagem e parametrização sobre os modelos

\begin{tabular}{|l|l|l|l|}
\hline REGRAS & \multicolumn{1}{|c|}{$\begin{array}{c}\text { Onde é } \\
\text { aplicada }\end{array}$} & $\begin{array}{c}\text { Família } \\
\text { utilizada }\end{array}$ & \multicolumn{1}{c|}{ Criação e ajuste } \\
\hline $\begin{array}{l}\text { Regra 1 } \\
\text { (Altura) }\end{array}$ & Na edificação & Level & $\begin{array}{l}\text { Foram alterados os nomes dos níveis da edificação, } \\
\text { acrescentado a palavra "Último" relativo ao piso do } \\
\text { último pavimento habitado. }\end{array}$ \\
\hline $\begin{array}{l}\text { Regra 2 } \\
\text { (Área) }\end{array}$ & $\begin{array}{l}\text { Na edificação } \\
\text { e seu entorno } \\
\text { imediato }\end{array}$ & $\begin{array}{l}\text { Room e } \\
\text { Tag Room }\end{array}$ & $\begin{array}{l}\text { Foram criados espaços, definindo o nome de cada } \\
\text { ocupação, para todos os pavimentos com os seguintes } \\
\text { nomes: Sala de Estar, Cozinha, Dormitório, Banho, } \\
\text { Hall, Escada e Passeio. }\end{array}$ \\
\hline $\begin{array}{l}\text { Regra 4 } \\
\text { Acesso da } \\
\text { viatura na } \\
\text { edificação) }\end{array}$ & $\begin{array}{l}\text { No entorno da } \\
\text { edificação }\end{array}$ & $\begin{array}{l}\text { Room e tag } \\
\text { room }\end{array}$ & $\begin{array}{l}\text { Foram criados passeios para definir a largura do } \\
\text { acesso da viatura. }\end{array}$ \\
\hline $\begin{array}{l}\text { Regra 6 } \\
\text { Saída de } \\
\text { emergência) }\end{array}$ & Na edificação & $\begin{array}{l}\text { Door e } \\
\text { Room }\end{array}$ & $\begin{array}{l}\text { Foram parametrizadas as portas de saída e chegada } \\
\text { para o cálculo da distância percorrida }\end{array}$ \\
\hline $\begin{array}{l}\text { Regra 11 } \\
\text { (Hidrante) }\end{array}$ & Na edificação & $\begin{array}{l}\text { Hidrante.rf } \\
\text { a Door e } \\
\text { Room }\end{array}$ & $\begin{array}{l}\text { Foram criadas portas fictícias: no abrigo do hidrante } \\
\text { e no ponto mais extremo do pavimento para a } \\
\text { verificação do comprimento da mangueira, e nas } \\
\text { extremidades de escadas para verificar a distância } \\
\text { percorrida até o abrigo do hidrante. }\end{array}$ \\
\hline
\end{tabular}

\section{Fase de execução}

As primeiras execuções de verificação automatizada de regras devem avaliar se os erros apontados são de preparação do modelo para a verificação. Busca-se confirmar se as propriedades, nomes e objetos necessários estão corretamente ajustados. Isso é denominado de pré-verificação do modelo. Essa verificação 
é primordial ao se detectarem possíveis erros de modelagem, parametrização, classificações e semânticas necessárias à realização da verificação final de regras. É na fase de execução que a hierarquização entre regras tem efeito. Nesta solução, a sequência de execução de regras de verificação de medidas de segurança contra incêndio baseia-se no Decreto estadual no 63.911 (SÃO PAULO, 2018), seguindo a hierarquia da Figura 7:

(a) o primeiro nível de hierarquia de regras inclui as regras gerais que verificam duas condições: a altura mínima da edificação, Regra 1, e a área total construída mínima da edificação, Regra 2. Essa dupla de regras representa a condição necessária para a entrada do Quadro 2 do Decreto estadual n ${ }^{\circ}$ 63.911 (SÃO PAULO, 2018). Se o modelo é aprovado nessas duas condições, segue-se para a verificação com as regras seguintes;

(b) o segundo nível de hierarquia de regras verifica o intervalo de altura em que a edificação se encontra, Regra 3. Se o modelo é aprovado nesta terceira regra, segue-se para a verificação das medidas contra incêndio apropriadas; e

(c) o terceiro nível de hierarquia de regras inclui regras (Regras 4 a 11) que avaliam as medidas de segurança sobre todo o modelo, sem ordem prioritária.

Realizando a análise de alinhamento com o método para verificação automatizada de códigos e normas de Eastman et al. (2009), nota-se coerência com a fase de execução como proposta no método. A fase de execução engloba:

(a) a verificação sintática do modelo; e

(b) uma disciplina de gerenciamento para coordenar a aplicação dos vários módulos de regras sobre o objeto de estudo.

\section{Relato de verificação}

Os resultados podem ser visualizados por imagens gráficas, por textos ou por relatórios a serem salvos nos formatos XLSX, PDF, RTF e BCF (.bcfZIP). A Figura 8 mostra a sequência de execução da regra no Solibri Model Checker. O item 1 indica o menu de execução da regra; o item 2 indica o ícone onde se executa a regra; o item 3 indica os ícones que representam a gravidade das violações de regras em três níveis: crítico, moderado e baixo, sendo este seguido por ícones do status da regra, ou seja, se esta foi aceita ou rejeitada; o item 4 indica o resultado da execução das regras de acordo com o indicado no item 3; os itens 5, 6, 7 e 8 indicam os problemas surgidos quando a regra é rejeitada. A Figura 9 apresenta um trecho de relatório textual emitido após um processo de verificação. Na análise de alinhamento com o método para verificação automatizada de códigos e normas de Eastman et al. (2009), nota-se atendimento parcial da fase de relato da verificação. Verifica-se que é possível reportar o resultado da verificação gráfica e textualmente. Entretanto, não se observa o mapeamento reverso para a regra não atendida na descrição textual.

\section{Discussão}

A aplicabilidade da solução num contexto interno, isto é, quanto à estruturação das quatro etapas propostas por Eastman et al. (2009), demonstrou alinhamento satisfatório. A modelagem no aplicativo Revit Architecture exigiu acréscimos de objetos e ajustes de propriedades associados às regras. $\mathrm{O}$ esclarecimento quanto ao subconjunto de objetos do modelo e propriedades necessárias para o processo de verificação automatizada fornece insumos para a elaboração futura da extração de MVD específico para essa verificação de código. Não houve problemas na interoperabilidade entre o Revit Architecture e o Solibri Model Checker. A plataforma Solibri Model Checker se mostrou de fácil usabilidade na criação e parametrização de regras. A impossibilidade de criar novas regras SOL do Solibri Model Checker não impôs deficiência à solução desenvolvida. Observa-se que existe mais de uma maneira de implementar uma medida de segurança com o Solibri Model Checker, mas optando-se pela estratégia 1 (Quadro 4) a quantidade de parametrização é mais eficiente. 
Figura 7 - Sequência de execução de regras elaboradas para a verificação das medidas de segurança contra incêndio

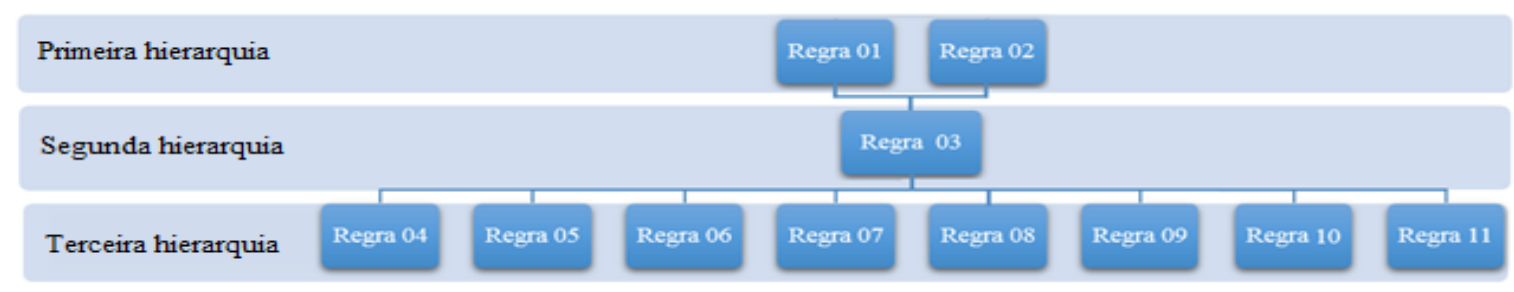

Fonte: Kater e Ruschel (2018, p. 3247).

Figura 8 - Sequência de execução de regras elaboradas para a verificação das medidas de segurança contra incêndio

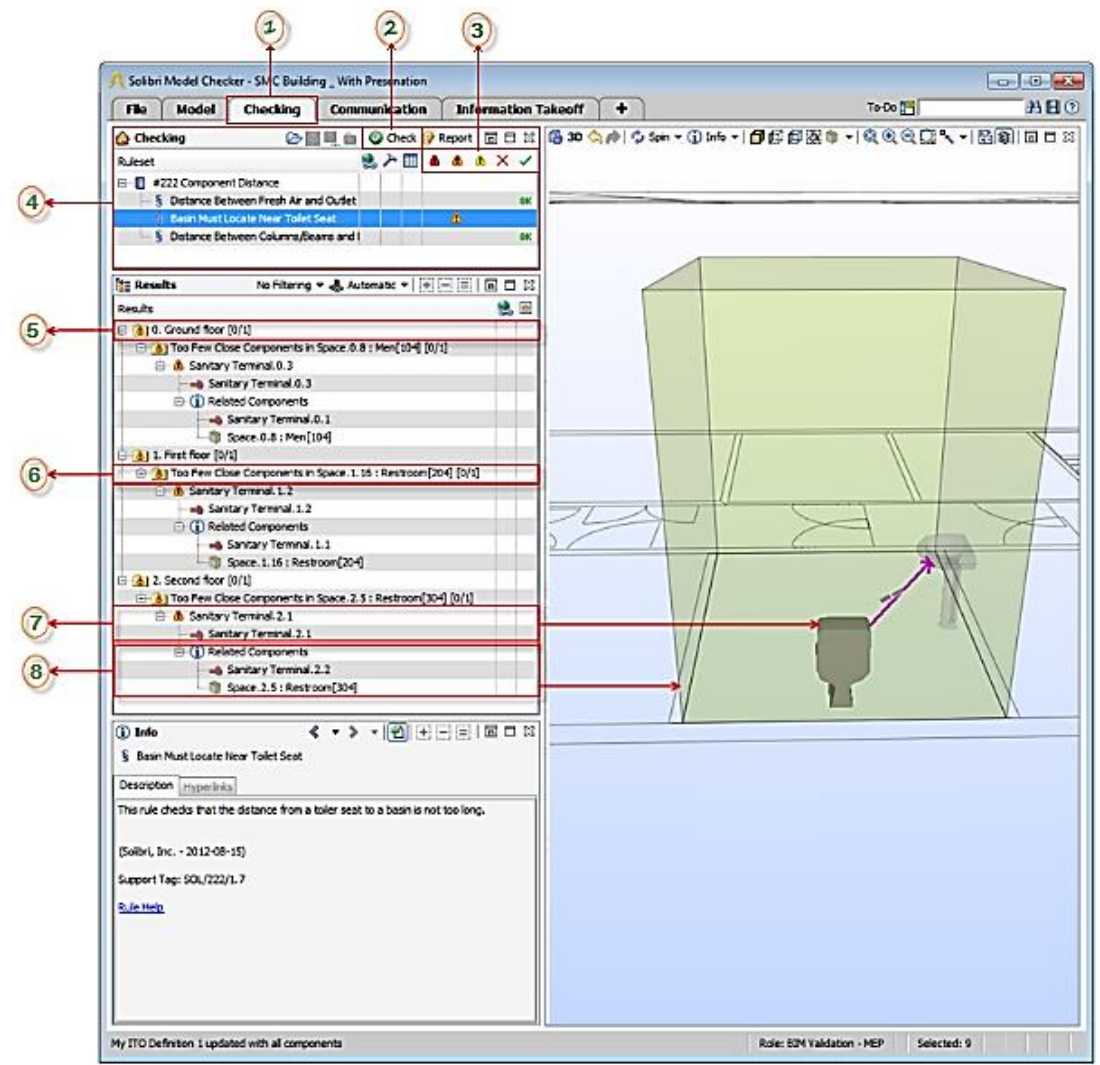

Fonte: Solibri Model Checker (2018).

Figura 9 - Trecho de um relatório textual de resultado de verificação no Solibri Model Checker

\begin{tabular}{|c|}
\hline 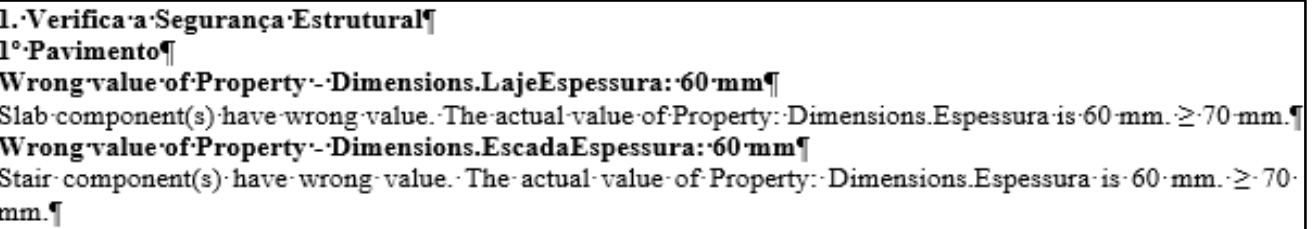 \\
\hline
\end{tabular}

Pode-se traçar uma equivalência com as quatro classes de regras propostas por Solihin e Eastman (2015) e as estratégias adotadas para a seleção de regras no Solibri Model Checker (Quadro 4), conjuntamente com as formas de derivação e composição das regras SOL. As estratégias 1 e 2, conjuntamente com derivações simples das regras SOL, implementam regras da classe 1, isto é, regras que exigem um único ou pequeno número de dados explícitos. Um requisito implementado por um conjunto de regras segundo as estratégias 1 e 2 enquadra-se na classe 2, isto é, regras que requerem valores de atributos derivados simples. A estratégia 
3 de implementação de regras equivale a regras da classe 3, isto é, regras que exigem estrutura de dados estendida, em que se faz uso de subterfúgios indiretos para avaliar o requisito pretendido. Solihin e Eastman (2015) também propõem uma quarta classificação: regras que exigem uma prova de solução. Para esse tipo de regra não foi aqui proposta uma estratégia de implementação.

Este estudo implementou as medidas de segurança contra incêndio para edificações residenciais multifamiliares com área superior a $750 \mathrm{~m}^{2}$ restrito a altura maior que $6 \mathrm{~m}$ ou igual a $12 \mathrm{~m}$ (Quadro 2). A medida de segurança de brigada de incêndio não foi implementada porque não é relativa ao projeto. As medidas de segurança de compartimentação vertical e controle de materiais de acabamento não foram implementadas porque não se aplicam ao projeto estudado em razão da faixa de altura dele. Todas as medidas restantes foram traduzidas em um conjunto de 11 regras segundo as classes 1,2 e 3 de Solihin e Eastman (2015). Dessa forma, o final desse processo resultou em $100 \%$ da verificação dos requisitos de projeto propostos neste estudo (Quadro 2, 4ª Coluna). Esse sucesso está associado às estratégias criadas de seleção de regras para implementação de um requisito (Quadro 4) e à preparação do modelo BIM compartilhando convenções associadas às regras de verificação, como sugerido por Eastman et al. (2009).

Foi realizado um exercício de generalização com a perspectiva de avaliar se a solução proposta neste estudo seria replicável ou adaptável a todas as medidas de segurança contra incêndio para todas as alturas de edificações residenciais multifamiliares do Quadro 2. Verificou-se que a total automatização em regras do Quadro 2 equivaleria à parametrização de 663 requisitos. Entre eles, 60 requisitos (Quadro 5) foram automatizados nesta pesquisa, abrangendo $7,8 \%$ dos requisitos automatizáveis. Entre os requisitos restantes, observaram-se alguns que requeriam parametrizações associadas à verificação de propriedades específicas, textos variados, fórmulas e condicionais. Registra-se que $1,4 \%$ dos requisitos são associados a condicionantes, não podendo ser implementados com as estratégias desenvolvidas e demonstradas, pois essas condicionais equivaliam à automação por regras da classe 4 segundo Solihin e Eastman (2015). Exemplos encontrados foram requisitos associados a exigências estruturais e visualização de sinalização. Dessa forma, considerando a porção de requisitos já implementados $(7,8 \%)$ e a porção não passível de implementação pela estratégia adotada $(1,4 \%)$, verificou-se que 90,8\% dos 663 requisitos levantados podem ser implementados por meio de regras do Solibri Model Checker considerando a estratégia adotada. Assim, a solução de automatização proposta e desenvolvida nesta pesquisa tem o potencial de viabilizar a real aplicação da norma de incêndio em projeto.

Essa solução completa as verificações de códigos para habitação já propostas: recomendações normativas de sistemas prediais de esgoto sanitário, água fria e quente (TAKAGAKI, 2016); especificações mínimas do Ministério das Cidades para unidades habitacionais PMCMV (FERNANDES; FORMOSO; TZORTZOPOULOS-FAZENDA, 2018); e norma de desempenho (ANDRADE E SILVA, 2017; SILVA JÚNIOR; MITIDIERI FILHO, 2018). Fernandes, Formoso e Tzortzopoulos-Fazenda (2018) relatam entre as causas de limitação da solução desenvolvida a não preparação do modelo BIM para o processo de verificação. Takagaki (2016), Andrade e Silva (2017) e Silva Júnior e Mitidieri Filho (2018) relatam limitações expressivas nas soluções desenvolvidas por complexidade do contexto ou subjetividade dos requisitos. Estas últimas limitações também ocorreram na solução proposta, mas com baixo impacto.

Segundo Solihin, Dimyadi e Lee (2018), um progresso significativo foi feito em relação aos sistemas automatizados de verificação de regras baseados em BIM. Existem várias abordagens que ampliam a eficácia de sistemas abertos e práticos de verificação de regras. Entretanto, a maioria se encontra em estado de prova de conceito para a implementação no mundo real. Os autores analisam vários sistemas de verificação de regras baseados em linguagem - entre eles o Solibri Model Checker - utilizando uma métrica de onze critérios para analisar as abordagens e sua prontidão para implementações do mundo real. A avaliação aponta que nenhuma abordagem única é atualmente capaz de abranger todo o espectro de requisitos para sistemas automatizados de verificação de regras, sugerindo a combinação de duas ou mais abordagens para viabilizar a realização de sistema de verificação de regras automatizado orientado por linguagem prática.

\section{Conclusão}

Esta pesquisa aproximou a teoria e a prática demonstrando, com rigor, a operacionalização do método para verificação automatizada de códigos e normas de Eastman et al. (2009) para regulamentações de incêndio do estado de São Paulo para edificações de uso residencial privativa multifamiliar. Foram utilizadas a ferramenta de modelagem BIM Revit Architecture e a plataforma de verificação Solibri. Os artefatos resultantes são: 
(a) o conjunto de regras de verificação (Quadro 5), que representam 100\% da automação das medidas de segurança contra incêndio para edificação com área superior a $750 \mathrm{~m}^{2}$ e altura entre $6 \mathrm{~m}$ e $12 \mathrm{~m}$, o que pode ser replicado para $90,8 \%$ do universo restante;

(b) a hierarquia entre regras que disciplina a coordenação da aplicação dos vários módulos de regras sobre o objeto de estudo;

(c) um exemplo de modelo BIM, caso-teste, para a solução, com a descrição da preparação necessária (Quadro 6); e

(d) o esclarecimento do subconjunto de objetos do modelo e propriedades necessárias para o processo de verificação automatizada que fornece indicativos de um MVD específico para essa verificação de código.

As questões de pesquisa inicialmente propostas puderam ser respondidas. Foi possível avaliar a exequibilidade da verificação automatizada de códigos para a validação de projetos de segurança contra incêndio usando o ferramental BIM. A implementação parcial das medidas de segurança contra incêndio, segundo o Decreto estadual $n^{\circ} 63.911$ (SÃO PAULO, 2018), para edificações residenciais multifamiliares representou 7,8\% dos requisitos para qualquer altura no mesmo quadro de área (Quadro 2). Entretanto, a solução proposta pode ser aplicada para quase a totalidade dos requisitos abrangendo qualquer altura do tipo de edificação avaliada, excluindo-se os requisitos das instruções técnicas e normas associadas às condicionais de exigências estruturais e visualização de sinalização. Dessa forma, visto que o processo corrente - manual ou apoiado com CAD - de verificação em projeto da segurança contra incêndio é impraticável para a totalidade de requisitos associados às instruções técnicas e normas associadas, a solução de automação proposta e desenvolvida em BIM nesta pesquisa resulta em grande avanço e contribuição, pois tem o potencial de viabilizar a real aplicação das medidas contra incêndio em projeto.

Além disso, 45\% das regras criadas exigiram preparação do modelo. Essa preparação viabilizou maior alcance da automação da verificação sobre o conjunto de medidas de segurança, demonstrando ser inviável utilizar um modelo sem preparação para o processo de verificação. Entretanto, essa preparação é inerente ao processo de verificação automatizada de códigos por regras (EASTMAN et al., 2009). Para mitigar limitações, Solihin, Dimyadi e Lee (2018) sugerem a combinação de duas ou mais abordagens para viabilizar a realização de sistema de verificação de regras automatizado orientado por linguagem prática.

\section{Referências}

ANDRADE E SILVA, F. P. de. Verificação automatizada dos requisitos de projetos da norma de desempenho pela plataforma BIM Solibri Model Checker. Belo Horizonte, 2017. 161 f. Dissertação (Mestrado em Construção Civil) - Escola de Engenharia, Universidade Federal de Minas Gerais, Belo Horizonte, 2017.

ASSOCIAÇÃO BRASILEIRA DE NORMAS TÉCNICAS. NBR 10898: sistema de iluminação de emergência. Rio de Janeiro, 2013a.

ASSOCIAÇÃO BRASILEIRA DE NORMAS TÉCNICAS. NBR 11861: mangueiras de incêndio: requisitos e métodos de ensaios. Rio de Janeiro, 1998.

ASSOCIAÇÃO BRASILEIRA DE NORMAS TÉCNICAS. NBR 12693: sistemas de proteção por extintores de incêndio. Rio de Janeiro, $2013 b$.

ASSOCIAÇÃO BRASILEIRA DE NORMAS TÉCNICAS. NBR 12779: mangueiras de incêndio: inspeção, manutenção e cuidados. Rio de Janeiro, 2009.

ASSOCIAÇÃO BRASILEIRA DE NORMAS TÉCNICAS. NBR 13434-1: sinalização de segurança contra incêndio e pânico Parte 1: Símbolos e suas formas, dimensões e cores. Rio de Janeiro, 2004a.

ASSOCIAÇÃO BRASILEIRA DE NORMAS TÉCNICAS. NBR 13434-2: sinalização de segurança contra incêndio e pânico: parte 2: símbolos e suas formas, dimensões e cores. Rio de Janeiro, 2004b.

ASSOCIAÇÃO BRASILEIRA DE NORMAS TÉCNICAS. NBR 13434-3: sinalização de segurança contra incêndio e pânico: parte 2: símbolos e suas formas, dimensões e cores. Rio de Janeiro, 2004c.

ASSOCIAÇÃO BRASILEIRA DE NORMAS TÉCNICAS. NBR 13714: sistemas de hidrantes e de mangotinhos, para combate a incêndio. Rio de Janeiro, 2000.

ASSOCIAÇÃO BRASILEIRA DE NORMAS TÉCNICAS. NBR 14432: exigências de resistência ao fogo de elementos construtivos de edificações: procedimento. Rio de Janeiro, 2001a. 
ASSOCIAÇÃO BRASILEIRA DE NORMAS TÉCNICAS. NBR 14859-1: laje pré-fabricada: requisitos: parte 1: lajes unidirecionais. Rio de Janeiro, 2016b.

ASSOCIAÇÃO BRASILEIRA DE NORMAS TÉCNICAS. NBR 15200: projeto de estruturas de concreto em situação de incêndio: procedimento. Rio de Janeiro, 2012.

ASSOCIAÇÃO BRASILEIRA DE NORMAS TÉCNICAS. NBR 15575-1: edificações habitacionais: desempenho: parte 1: requisitos gerais. Rio de Janeiro, 2013c.

ASSOCIAÇÃO BRASILEIRA DE NORMAS TÉCNICAS. NBR 17240: sistemas de detecção e alarme de incêndio: projeto, instalação, comissionamento e manutenção de sistemas de detecção e alarme de incêndio: requisitos. Rio de Janeiro, 2010.

ASSOCIAÇÃO BRASILEIRA DE NORMAS TÉCNICAS. NBR 6118: projeto de estruturas de concreto: procedimento. Rio de Janeiro, 2014.

ASSOCIAÇÃO BRASILEIRA DE NORMAS TÉCNICAS. NBR 6136: blocos vazados de concreto simples, para alvenaria: requisitos. Rio de Janeiro, 2016a.

ASSOCIAÇÃO BRASILEIRA DE NORMAS TÉCNICAS. NBR 9050: acessibilidade a edificações, mobiliário, espaços e equipamentos urbanos. Rio de Janeiro, 2015.

ASSOCIAÇÃO BRASILEIRA DE NORMAS TÉCNICAS. NBR 9077: saídas de emergência em edifícios. Rio de Janeiro, 2001b.

BALDAUF, J. P. Proposta de método para modelagem de requisito de clientes de empreendimentos habitacionais de interesse social usando BIM. Porto Alegre, 2013. Dissertação (Mestrado em Engenharia Civil) - Programa de Pós-Graduação em Engenharia Civil, Universidade Federal do Rio Grande do Sul, Porto Alegre, 2013.

BALDAUF, J. P.; FORMOSO, C. T.; MIRON, L. I. G. Modelagem de requisitos de clientes de empreendimentos habitacionais de interesse social com o uso de BIM. Ambiente Construído, Porto Alegre, v. 13, n. 3, p. 177-195, jul./set. 2013.

BRASIL. Ministro de Estado do Trabalho. Aprova as Normas Regulamentadoras - NR - do Capítulo V, Título II, da Consolidação das Leis do Trabalho, relativas à Segurança e Medicina do Trabalho. Portaria ${ }^{\circ}$ 3214 de 08 de junho de 1978. Diário Oficial da União, 06 julho 1978.

CAMPINAS. Lei Complementar $\mathbf{n}^{\mathbf{0}} \mathbf{9}, 23$ de dezembro de 2003. Dispõe sobre o código de projetos e execuções de obras e edificações do município de Campinas. Disponível em: http://leismunicipa.is/jnamd. Acesso em: 10 jan. 2017.

CORPO DE BOMBEIROS DA POLÍCIA MILITAR DO ESTADO DE SÃO PAULO. Cartilha de orientações básicas noções de prevenção contra incêndio dicas de segurança. São Paulo, maio 2011. Disponível em: http://www.ccb.policiamilitar.sp.gov.br/icb/wp-

content/uploads/2017/02/Cartilha_de_Orientacao.pdf. Acesso em: 10 fev. 2017.

DRESCH, A.; LACERDA, D. P.; ANTUNES JUNIOR, J. A. V. Design Science Research: método de pesquisa para avanço da ciência e tecnologia. Porto Alegre: Bookman, 2015.

EASTMAN, C. M. et al. Automatic rule-based checking of buildings designs. Automation in Construction, v. 18, n. 8, p. 1011-1033, dez. 2009.

FERNANDES, G. von der H.; FORMOSO, C. T.; TZORTZOPOULOS-FAZENDA, P. Método para verificação automatizada de requisitos em empreendimentos Habitacionais de Interesse Social. Ambiente Construído, Porto Alegre, v. 18, n. 4, p. 259-278, out./dez. 2018.

KATER, M.; RUSCHEL, R. C. Verificação automática das medidas de segurança contra incêndio do estado de São Paulo no projeto de habitação multifamiliar. In: ENCONTRO NACIONAL DE TECNOLOGIA DO AMBIENTE CONSTRUÍDO, 17., Foz do Iguaçu, 2018. Anais [...] Porto Alegre: Antac, 2018.

KATER, M.; RUSCHEL, R. C. Avaliando a aplicabilidade de BIM para a verificação da norma de segurança contra incêndio em projeto de habitação multifamiliar. In: ENCONTRO NACIONAL DE TECNOLOGIA DO AMBIENTE CONSTRUIIDO, 15., Maceió, 2014. Anais [...] Porto Alegre: ANTAC. 2014.

LUKKA, K. The Constructive Research Approach. In: OJAL, L.; HILMOLA, O-P. (ed.). Case study research in logistics. Turku School of Economics and Business Administration, Series B1, p. 83-101, 2003. 
MAINARDI NETO, A. I. Verificação de regras para aprovação de projetos de arquitetura em BIM para estações de metrô. São Paulo, 2016. 124 f. Dissertação (Mestrado em Inovação na Construção Civil) Escola Politécnica, Universidade de São Paulo, São Paulo, 2016.

MARCH, S. T.; SMITH, G. F. Design and natural science research on information technology. Decision Support Systems, v. 15, n. 4, p. 251-266, dec. 1995.

ONO, R. Parâmetros para garantia da qualidade do projeto de segurança contra incêndios em edifícios altos. Porto Alegre. Ambiente construído, v. 7, n. 1, p. 97-113, jan./mar. 2007.

SANTOS, R.; COSTA, A. A.; GRILO, A. Bibliomatric analysis and review of Building Information Modelling literature published between 2005 and 2015. Automation in Construction, v. 80, p. 118-136, ago. 2017.

SÃO PAULO (Estado). Decreto estadual no 63.911, 10 de dezembro de 2018, que institui o Regulamento de Segurança contra Incêndio das edificações e áreas de risco no Estado de São Paulo e dá providências correlatas. Disponível em: https://www.al.sp.gov.br/repositorio/legislacao/decreto/2018/decreto-6391110.12.2018.html. Acesso em: 2 fev. 2019.

SÃO PAULO (Estado). Secretaria de Estado dos Negócios da Segurança Pública. Instrução técnica No. 06/2011: acesso de viatura na edificação e área de risco. São Paulo: Polícia Militar do Estado de São Paulo, Corpo de Bombeiros, 2011a. Disponível em:

http://www.corpodebombeiros.sp.gov.br/dsci_publicacoes2/_lib/file/doc/IT_06_2011.pdf. Acesso em: 12 ago. 2013.

SÃO PAULO (Estado). Secretaria de Estado dos Negócios da Segurança Pública. Instrução técnica No. 08/2011: resistência ao fogo dos elementos de construção. São Paulo: Polícia Militar do Estado de São Paulo, Corpo de Bombeiros, 2011b. Disponível em:

http://www.corpodebombeiros.sp.gov.br/dsci_publicacoes2/_lib/file/doc/IT_08_2011.pdf. Acesso em: 12 ago. 2013.

SÃO PAULO (Estado). Secretaria de Estado dos Negócios da Segurança Pública. Instrução técnica № 11/2011: saídas de emergência. São Paulo: Polícia Militar do Estado de São Paulo, Corpo de Bombeiros, 2011c. Disponível em:

http://www.corpodebombeiros.sp.gov.br/dsci_publicacoes2/_lib/file/doc/IT_11_2011.pdf. Acesso em: 12 ago. 2013.

SÃO PAULO (Estado). Secretaria de Estado dos Negócios da Segurança Pública. Instrução TÉCNICA № 18/2011: iluminação de emergência. São Paulo: Polícia Militar do Estado de São Paulo, Corpo de Bombeiros, 2011d. Disponível em:

http://www.corpodebombeiros.sp.gov.br/dsci_publicacoes2/_lib/file/doc/IT_18_2011.pdf. Acesso em: 14 ago. 2013.

SÃO PAULO (Estado). Secretaria de Estado dos Negócios da Segurança Pública. Instrução técnica № 19/2011: sistema de detecção e alarme de incêndio. São Paulo: Polícia Militar do Estado de São Paulo, Corpo de Bombeiros, 2011e. Disponível em:

http://www.corpodebombeiros.sp.gov.br/dsci_publicacoes2/_lib/file/doc/IT_19_2011.pdf. Acesso em: 16 ago. 2013.

SÃO PAULO (Estado). Secretaria de Estado dos Negócios da Segurança Pública. Instrução técnica № 20/2011: sinalização de emergência. São Paulo: Polícia Militar do Estado de São Paulo, Corpo de Bombeiros, 2011f. Disponível em:

http://www.corpodebombeiros.sp.gov.br/dsci_publicacoes2/_lib/file/doc/IT_20_2011.pdf. Acesso em: 16 ago. 2013.

SÃO PAULO (Estado). Secretaria de Estado dos Negócios da Segurança Pública. Instrução técnica № 21/2011: sistema de proteção por extintores de incêndio. São Paulo: Polícia Militar do Estado de São Paulo. Corpo de Bombeiros, 2011g. Disponível em:

http://www.corpodebombeiros.sp.gov.br/dsci_publicacoes2/_lib/file/doc/IT_08_2011.pdf. Acesso em: 18 ago. 2013. 
SÃO PAULO (Estado). Secretaria de Estado dos Negócios da Segurança Pública. Instrução TÉCNICA № 22/2011. Sistemas de hidrantes e de mangotinhos para combate a incêndio. São Paulo: Polícia Militar do Estado de São Paulo, Corpo de Bombeiros, 2011h. Disponível em: http://www.corpodebombeiros.sp.gov.br/dsci_publicacoes2/_lib/file/doc/IT_22_2011.pdf. Acesso em: 18 ago. 2013.

SEITO, A. I. Legislação, regulamentação e normas técnicas. GSI/NUTAU/USP. 16 de abril de 2009. Disponível em: http://www.lmc.ep.usp.br/grupos/gsi/wpcontent/artigos/legislacao/regulamentacao_normas.pdf. Acesso em: 5 nov. 2013.

SILVA JUNIOR, M. A.; MITIDIERI FILHO, C. V. Verificação de critérios de desempenho em projetos de arquitetura com a modelagem BIM. PARC Pesquisa em Arquitetura e Construção, v. 9, n. 4, p. 334-343, 1 dez. 2018.

SOLIBRI MODEL CHECKER. Solibri Model Checker getting started V9.5. Disponível em: http://www.solibri.com/solibri-model-checker.html. Acesso em: 12 mar. 2018.

SOLIHIN, W; DIMYADI, J; LEE, Y-C. In search of open and practical language-driven BIM-based automated rule checking systems. In: MUTIS, I.; HARTMANN, T. (ed.). Proceedings of the $\mathbf{3 5}^{\text {th }}$. advances in informatics and computing in civil and construction engineering. Cham: Springer, 2018.

SOLIHIN, W; EASTMAN, C. M. Classification of rules for automated BIM rule checking development. Automation in Construction, v. 18, p. 69-82, may 2015.

SOLIMAN JUNIOR, J. Framework para suporte à verificação automatizada de requisitos regulamentares em projetos hospitalares. Porto Alegre, 2018. Dissertação (Mestrado em Engenharia Civil) - Programa de Pós-Graduação em Engenharia Civil, Universidade Federal do Rio Grande do Sul, Porto Alegre, 2018.

TAKAGAKI, C. Regras de verificação e validação de modelos BIM para sistemas prediais hidráulicos e sanitários. São Paulo, 2016. 113 f. Dissertação (Mestrado em Inovação da Construção Civil) - Escola Politécnica, Universidade de São Paulo, São Paulo, 2016.

VAISHNAVI, V.; KUECHLER, W.; PETTER, S. (ed.). Design Science Research in Information Systems. 2019. Disponível em: http://www.desrist.org/design-research-in-information-systems/. Acesso em: 18 ago. 2020.

YALCINKAYA, M.; SINGH, V. Patterns and trends in Building Information Modeling (BIM) research: a latent semantic analysis. Automation in Construction, v. 59, p. 68-80, 2015.

\section{Agradecimentos}

Agradecemos ao Conselho Nacional de Desenvolvimento Científico e Tecnológico (CNPq) pelo suporte a esta pesquisa por meio de bolsa de produtividade em pesquisa (PQ).

Marcel Kater

Programa de Pós-graduação em Engenharia Civil | Universidade Estadual de Campinas | Rua Saturnino de Brito, 224 | Campinas - SP Brasil | CEP 13083-889 | Tel.: (11) 97652-6482 | E-mail: marcel.kater@hotmail.com

Regina Coeli Ruschel

Faculdade de Engenharia Civil, Arquitetura e Urbanismo | Universidade Estadual de Campinas | Tel.: (19) 99114-9264 | E-mail: ruschel@unicamp.br

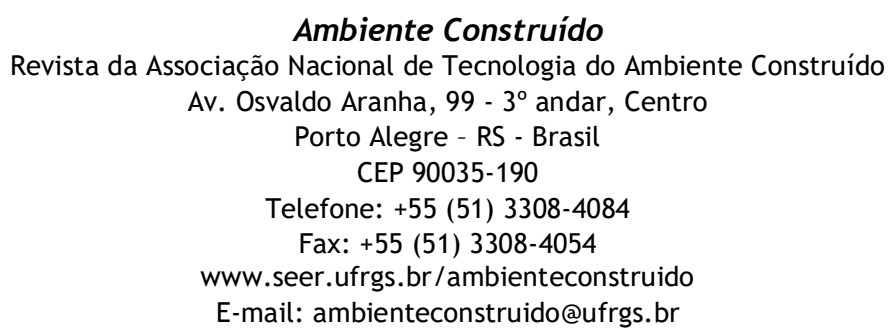

